\title{
Escrita teclada $x$ escrita padrão na produção textual: a experiência de adolescentes brasileiros*
}

\author{
Ana Lucia Gomes \& Jane Correa \\ Universidade Federal do Rio de Janeiro, Brasil
}

\begin{abstract}
Resumo
O computador associado à internet vem produzindo transformações no ato de escrever, conduzindo a produção escrita em direção à rapidez e velocidade de execução. Em decorrência das demandas do uso dos aplicativos de comunicação instantânea, surgem novos gêneros textuais, investindo a escrita de características linguísticas específicas, visando tornar a comunicação através do texto digital mais dinâmica e funcional. O presente trabalho discute o emprego da escrita teclada por adolescentes como vinculada ao gênero textual digital, contextualizada pela cultura eletrônica, possibilitando a produção discursiva na internet. Argumenta-se que escrita teclada não seria transposta necessariamente a outros contextos discursivos, como por exemplo, o escolar, sugerindo, desta forma, a ocorrência de um processo de legitimação das escolhas lingüísticas em função do contexto sociocomunicativo.
\end{abstract}

Palavras-chave

Escrita teclada; Gênero textual digital; Cultura eletrônica; Adolescentes

\section{Introdução}

Todo texto possui um propósito discursivo que se concretiza a partir de uma forma específica, os gêneros de texto, através da qual o leitor pode 
predizer e interpretar as intenções do autor, assim como compreender o seu conteúdo, pela construção de um sentido comum (Koch \& Elias, 2006).

Os gêneros de texto consistem em modelos de ação social que se originam a partir das relações estabelecidas entre o contexto enunciativo, a linguagem comum aos participantes do discurso e o seu uso intencional (Marcuschi, 2005b). Sua função visa ordenar e estabilizar o texto por meio de sua forma característica, conteúdo, estilo e propriedade funcional (Koch \& Elias, 2006). Observa-se, no entanto, que os gêneros de texto, por serem dinâmicos e flexíveis, investem o discurso de uma estabilidade relativa, pois sua forma pode ser modificada para se ajustar às variações das atividades discursivas do sujeito.

Em função do gênero textual se originar a partir das práticas socioculturais, sua utilização ocorre nas mais diferentes esferas da sociedade, sendo observado em vários setores: na família, através das certidões de casamento ou nascimento; nas escolas, pelos boletins e listas de aprovação (Marcuschi, 2006). As inúmeras situações interativas que o sujeito vivencia ao longo do dia, como conversar com o jornaleiro, fazer compras, pagar uma conta ou ler o seu e-mail, permitem a ele entrar em contato com uma variedade cada vez mais ampla de gêneros textuais (revistas, boletins, receitas, jornais, piadas, encartes, tabelas, relatórios). Tais variedades permitem que o sujeito (re)conheça-os e compreenda a sua função estruturante junto ao texto. Assim, o sujeito ao planejar a sua escrita realiza uma escolha, podendo ser intuitiva ou criteriosa, acerca do gênero mais apropriado para expressar suas idéias, tendo em mente dois aspectos básicos: a quem seu texto se destina e o modo como pretende transmitir sua mensagem (Dell'Isola, 2007; Marcuschi, 2005a). A partir destes elementos o sujeito elabora seu texto, podendo encerrá-lo através da forma de um bilhete, considerando que a mensagem seja de caráter informal, ou, então, utilizar um memorando considerando uma relação formal de trabalho.

Os gêneros de texto também funcionam como demarcadores das relações de poder existentes na cultura, indicando quem, a partir de um dado contexto, é legitimado a usar certas formas para expressar um conteúdo específico, tais como a emissão de um parecer técnico por um especialista ou um boletim de ocorrência registrado por um policial (Dell'Isola, 2007; Marcuschi, 2006). 
O avanço tecnológico na área da informação e comunicação vem interferindo diretamente nas atividades comunicativas humanas. Se antes da década de 90 , de modo geral, a forma mais rápida de comunicação envolvendo tecnologia versava sobre o uso do telefone fixo, a partir de 1990, com o advento da Internet nos deparamos com um recurso inovador (Marcuschi, 2005b). Através desta ferramenta passamos a interagir com mais rapidez, podendo inclusive conversar virtualmente com uma ou mais pessoas ao mesmo tempo, além de obter acesso a uma fonte quase que inesgotável de informações consultando à rede World Wide Web (WWW).

O contínuo progresso tecnológico provê cada vez mais facilidade de acesso à Internet, através de diferentes suportes, como aparelhos telefônicos celulares, notebooks ou palmtops. Estes suportes eletrônicos portáteis permitem ao usuário se conectar à Internet a qualquer hora e qualquer lugar tornando cada vez mais intensa a relação que se estabelece entre tecnologia e comunicação, permitindo a ele entrar em contato com novas formas de ação através da linguagem, como as listas de discussão e chat aberto, associadas ao contexto da cultura eletrônica (Eisenkraemer, 2006). Alguns gêneros textuais vinculados ao contexto digital tomam como referência os gêneros textuais já existentes (Costa, 2005; Marcuschi, 2005a). Por isso, encontramos semelhanças entre as formas de alguns destes gêneros digitais e os tradicionais, como se observa ocorrer entre o e-mail e a carta, as mensagens deixadas no Orkut e os bilhetes, ou ainda o blog e o diário pessoal (Pereira \& Moura, 2005).

A comunicação pela Internet ocorre essencialmente pela escrita tendo como canal os aplicativos de comunicação mediados por computador que podem ser de dois tipos: síncronos ou assíncronos. Os aplicativos síncronos permitem ao sujeito interagir em tempo real com apenas um ou vários interlocutores simultaneamente, como se verifica através do uso do MSN e Chat. Os dispositivos assíncronos não possibilitam o diálogo em tempo real, por gerar um intervalo de tempo entre o envio da mensagem e o seu retorno pelo interlocutor, como ocorre com o uso do e-mail e blog (Baron, 2005).

Para conversarem através da Internet os adolescentes usam vários tipos de gêneros de texto digitais. Com freqüência, seus textos vêm sendo produzidos de modo alternativo e casual, utilizando a linguagem escrita de forma mais simplificada e com várias transgressões, como iniciar frases com 
letra minúscula ou, então, não acentuar as palavras (Costa, 2005; Bolter, 2001; Lee, 2007). A forma não-convencional de escrever na Internet se transformou em um modismo entre os mais jovens, caracterizando, assim, a escrita adolescente nos canais digitais de comunicação.

O uso descompromissado da escrita, no que diz respeito às suas normas, e o aumento crescente do número de adeptos a este modo de registro têm despertado a atenção da comunidade científica para a emergência de um novo estilo de escrita denominado como "escrita teclada", "escrita da Internet" ou, ainda, "Internetês" (Coscarelli, 2003; Freire, 2003; Merchant, 2001; Lee, 2007).

A origem da escrita teclada está relacionada a diversos fatores. Um destes fatores seria, possivelmente, os obstáculos que o emprego da escrita padrão poderiam impor às interações que ocorrem em tempo real na Internet. Por exemplo, através do chat o adolescente pode teclar com vários amigos ao mesmo tempo. Neste contexto, se ele escrevesse em concordância às regras gramaticais ou de pontuação levaria muito tempo para teclar sua mensagem e isso culminaria no possível abandono da conversa pelos seus interlocutores.

Outro fator que pode ter estimulado o emprego da escrita teclada consiste no fato dos adolescentes buscarem aproximar a escrita das características do discurso oral, considerando que quanto mais casual for um gênero de texto maior é a tendência do texto escrito se aproximar do texto falado (Eisenkraemer, 2006). Para isto teclam as palavras conforme são pronunciadas, assim como utilizam artifícios gráficos (desenhos e símbolos) para representar gestos e expressões que naturalmente acompanham a fala em uma situação presencial (Lotherington \& Xu, 2004; Marcuschi, 2005b). Dessa forma, ao longo dos textos escritos na Internet pelos adolescentes encontramos o uso de: a) simplificações fonéticas (kero/quero; axo/acho), b) onomatopéias (Snif!/ARGH!), c) abreviações (q/que; vc-c/você) e de, d) símbolos e desenhos (S2/coração; 0:)/ anjo; :)/feliz; :(/triste).

$\mathrm{O}$ fato dos adolescentes teclarem preocupando-se apenas com a comunicação em si, ou seja, em se fazerem entender e escrever de forma rápida, deixando a norma da língua em segundo plano, vem preocupando pais e educadores sobre a possibilidade de comprometerem a qualidade da sua escrita através do uso freqüente da Internet para interagirem socialmente 
(Marcuschi, 2005b; Merchant, 2001; Farmer, 2003; Freitag \& Fonseca e Silva, 2006). No contexto eletrônico os adolescentes também experimentam uma nova relação com o processo de escrita, onde não revisam o texto, assim como não se preocupam em escrevê-lo de acordo com os aspectos sintáticos, gramaticais ou ortográficos da escrita padrão. Para alguns responsáveis e professores, o contato excessivo com o Internetês poderia fazer com que os adolescentes, por força do hábito, "desaprendessem" a forma padrão de grafar e produzir textos. Em função disso, empregariam ao longo de suas anotações pessoais e escolares as várias transgressões lingüísticas observadas na escrita da Internet.

O presente trabalho procura uma maior compreensão acerca dos usos da escrita em diferentes gêneros de texto, discutindo o emprego da escrita teclada e da escrita padrão por adolescentes. Através de um estudo exploratório, de natureza qualitativa, examinamos se adolescentes, a partir do uso freqüente da Internet, acabam por transpor espontaneamente a forma como escrevem no contexto digital para as situações formais de escrita no contexto escolar. Consideramos a possibilidade de não haver transposição necessária da escrita teclada para a escrita padrão, por tratarmos de escritas inseridas em contextos de produção diferenciados e regulados por gêneros textuais distintos, onde a primeira (escrita teclada) vincula-se ao contexto digital, e a segunda, escrita padrão, aplica-se ao contexto impresso ou manuscrito que a prescrevem.

\section{Método}

Foram realizadas entrevistas individuais com oito adolescentes, sendo três garotos e cinco garotas, na faixa etária dos 12 aos 16 anos, estudantes da rede particular de ensino, que atende a uma comunidade de status social médio da cidade do Rio de Janeiro. Os participantes, apesar de freqüentarem a mesma escola, não se conheciam pessoalmente e também não mantinham contato via Internet. Todos possuíam computador próprio e acesso freqüente à Internet em banda larga, gastando, em média, entre 4-5 horas do dia conectados à rede. Os adolescentes também utilizavam o computador na escola, possuindo aulas semanais de informática, com acesso à Internet para fazerem suas pesquisas escolares. 
Através da entrevista buscamos examinar as várias formas de uso do computador conectado à Internet pelos adolescentes, assim como em quais contextos discursivos escreviam seus textos. As entrevistas foram realizadas individualmente, tendo sido usado um questionário, como roteiro, contendo perguntas abertas. As questões realizadas abordaram a freqüência com que os adolescentes acessam a Internet, os sítios que costumam navegar, o que pensam sobre a escrita teclada utilizada na Internet e se há possibilidade de se confundir a escrita manuscrita pautada na norma culta da língua portuguesa e a escrita da Internet durante a execução de suas atividades escolares.

A orientação dada aos adolescentes durante a entrevista foi a de que não haveria respostas certas ou erradas, tendo em vista que o importante era o seu ponto de vista sobre o assunto que iríamos discutir. Dessa forma, as perguntas foram realizadas deixando-os falar livremente sobre o assunto. As respostas foram registradas verbatim pelo entrevistador, com consentimento prévio dos adolescentes.

Além da entrevista, foram analisados os cadernos escolares das disciplinas de português, história e biologia, para verificarmos como seriam realizados os registros escritos pelos adolescentes na sala de aula. Essas disciplinas foram escolhidas por apresentarem comumente bastante material escrito, tais como resumos e cópias de textos, o que nos permitiria verificar a ocorrência de transposição das variações lingüísticas usadas no contexto discursivo digital para o contexto acadêmico.

A escrita da Internet foi analisada a partir do ORKUT, tendo em vista ser um aplicativo de comunicação instantânea usado por todos os adolescentes participantes do presente estudo. O ORKUT consiste em uma rede social de acesso gratuito criado em 2004 que objetiva fazer com que seus usuários ampliem seus laços de amizade (Komeso, no prelo; Wikipedia, 2007). O sistema possui atualmente mais de sessenta milhões de usuários cadastrados, onde aproximadamente $55 \%$ deste número são brasileiros (Wikipedia, 2007). Os textos foram retirados das páginas de recados e depoimentos do ORKUT com consentimento dos adolescentes entrevistados. A análise realizada nestes textos implicou em descrever as marcas lingüísticas da escrita empregada pelos adolescentes. No presente trabalho, os depoimentos dos adolescentes, bem como suas produções escritas, foram identificados por nomes fictícios para manter a privacidade dos entrevistados. 


\section{Resultados}

Nas entrevistas, não foram observadas diferenças expressivas nas respostas dos adolescentes ao questionário em função do gênero e da idade. Para os adolescentes entrevistados o uso freqüente da Internet visa basicamente duas funções: a de comunicação e a de pesquisa para trabalhos escolares. No entanto, a função mais relevante da Internet para os entrevistados é a voltada para a comunicação, através principalmente do uso de aplicativos de comunicação, mediada por computador, de caráter simultâneo, ou seja, que permitem o diálogo em tempo real (Freire, 2003; Araújo, 2006, Merchant, 2001; Gross, 2004; Greenfield \& Yan, 2006). A Internet como canal de comunicação disponibiliza novas formas de sociabilidades, permitindo ao adolescente aumentar o número de pessoas que conhece através das interações discursivas escritas que ocorrem pelos vários gêneros de texto digitais. Os adolescentes entrevistados usam com grande freqüência os gêneros MSN e o ORKUT. Analisamos com maiores detalhes a comunicação que ocorre através do ORKUT, examinando a forma como os adolescentes vêm escrevendo neste contexto dialógico digital.

O ORKUT permite ao usuário fazer parte de várias comunidades cujos temas sejam de seu interesse, tais como política, música, cinema, atualidades, lugares, literatura, dentre outras. As comunidades realizam fóruns de discussão relativos ao tema de que tratam. Fazer parte de uma comunidade torna-se uma excelente possibilidade de ampliar a rede social dos usuários (Meneses, 2004). Cada um dos adolescentes entrevistados possuía em média 517 amigos e participava em torno de 146 comunidades.

Além dos aplicativos de comunicação instantânea, o computador conectado à Internet também apresenta outro grande atrativo para os adolescentes: a possibilidade de realizar várias tarefas simultaneamente, fazendo com que eles passem grande parte do seu dia livre na frente da tela do computador (Merchant, 2001).

Posso fazer muitas coisas... visito o ORKUT, MSN, ao mesmo tempo estou fazendo pesquisa no GOOGLE, meu procurador da Internet, faço visitas a outros sites, baixo arquivos, troco com meus amigos, pego músicas e letras de músicas, enfim, faço muita coisa ... na minha tela fica um monte de janela aberta e às vezes até me confundo e esqueço de coisas que estava fazendo (Daniela, 13 anos). 
Em função dessas múltiplas formas de ação que a Internet oferece aos seus usuários, não é de se estranhar que alguns adolescentes optem por fazer de tudo através do computador, como, por exemplo, navegar por diversos sites, se distrair com jogos on ou off-line e, principalmente, conversar com seus amigos.

Através da Internet os adolescentes conversam sobre os mais variados assuntos, desde os acontecimentos da escola, assim como, combinam entre eles sobre o que fazer nas horas vagas (Lee, 2007). Alguns adolescentes declararam que o computador substituiu as longas conversas realizadas por telefone, tendo em vista que alguns aplicativos permitem a conversa ao mesmo tempo com um número variado de pessoas, tornando a comunicação via Internet muito mais interessante (Descy, 2007).

A criação dos dispositivos eletrônicos para a comunicação trouxe novas possibilidades discursivas (Freitas, 2000; Merchant, 2001). Através de sua participação no ORKUT, por exemplo, os adolescentes transformam o uso da linguagem escrita sem comprometerem a qualidade do diálogo entre seus participantes, apesar das inúmeras transgressões lingüísticas observadas. No depoimento a seguir, escrito para um amigo por uma das adolescentes entrevistadas, observa-se a ocorrência de elementos que quando utilizados juntos contextualizam a escrita na cultura digital. Verifica-se a presença de frases curtas e objetivas, ausência de acentuação gráfica (naum/não, ehh/é), uso de abreviações (mto/muito, vcê,vc/você, nka/nunca, td/tudo, tmpo/tempo, mtaçoo/muitaço, bjinhuss/beijinhos) e de transcrições fonéticas (ki/que, kem/quem, naum/não, ker/quer), o que confere praticidade ao teclar. Nota-se, também, o uso de caixa alta (GRANDE), alongamento de letras (amigoo, meuu, ocupandoo, perdidoo, Amaa, mtoo, beeem, aeeww, amooo, mtaçoo, bjinhuss), uso repetitivo dos sinais de pontuação e recursos gráficos (!!, ??, ;)/piscadela, ;*/piscadela com beijo, s2/desenho do coração, =D/rosto feliz, عï3/ borboleta), utilizados com a função de auxiliar a expressão de emoções através da escrita, assim como enfatizar um determinado conteúdo do texto:

\footnotetext{
Uma pessoinha ki eu conheci numa situação tão inusitada, mas ki se tornou mto importante pra mim Esse seu jeioo de ser .. me fez ver em vcê um GRANDE amigoo Sua amizade pra mim vale ouro e eu naum kero perde — la nka viiu ! ;) Cada dia ki passa, vc vem ocupandoo mais e mais meuu s2 !!
} 


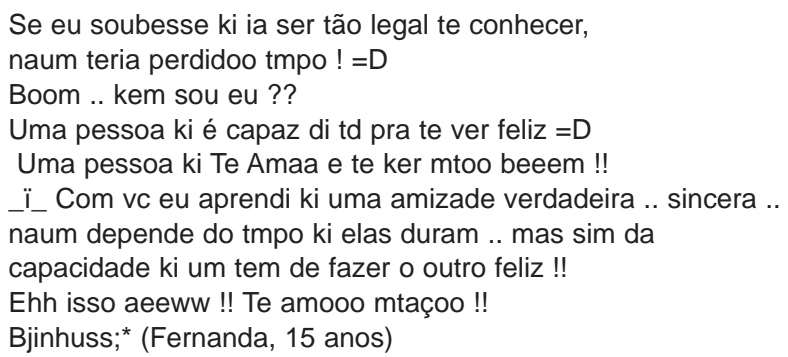

A análise dos recados que os adolescentes entrevistados possuem no ORKUT revela que as variações lingüísticas apresentadas acima abreviações, ausência de sinais gráficos e alongamento de letras - ocorrem com bastante regularidade na escrita dos jovens. Porém, tais variações não estavam presentes em todos os recados. Foi observada, em menor número, a ocorrência de recados escritos de acordo com a norma padrão do Português Brasileiro. Alguns adolescentes preferiram escrever de forma convencional, optando pela escrita alternativa apenas quando houvesse "necessidade", ou seja, quando precisassem escrever rápido por estarem conversando com mais de um amigo na rede ou porque quisessem escrever de forma mais prática com economia de movimentos. Denise (14 anos) ilustra essa escolha:

Prefiro escrever "certo", mesmo no ORKUT ou MSN, só escrevo "errado" quando estou cansada ou quando preciso escrever muito rápido. O que mais faço é escrever abreviado.

Com relação ao que pensam sobre a escrita teclada, os adolescentes entrevistados a concebem como "errada", se comparada à escrita formal utilizada na escola, ou seja, se analisada fora do contexto digital. É consenso que a escrita teclada consiste em uma forma alternativa de comunicação que se adapta à urgência da Internet provendo liberdade quanto à forma como seus usuários podem escrever seus textos. Carlos (16 anos), com seu depoimento, ilustra essas observações:

Eu uso a escrita da Internet para conversar com meus amigos, porque fica mais fácil, menos cansativo e não me preocupo em escrever tudo certinho, tim-tim por tim-tim. O que importa é o outro entender o que quero dizer.

$\mathrm{Na}$ análise dos cadernos escolares observamos como os adolescentes fazem suas anotações de classe, considerando que a escola em que estudam não tem como prática pedagógica vistoriar os cadernos para verificar como os 
registros são realizados. Logo, os adolescentes entrevistados anotavam as matérias da forma como achassem melhor, podendo utilizar qualquer forma de registro para atender melhor a sua demanda em particular.

Os adolescentes entrevistados durante a cópia ou realização das tarefas escolares não escreviam de forma abreviada, respondendo às questões propostas pelo professor valendo-se do emprego da norma padrão da língua portuguesa. Nas situações em que os alunos pareciam ter pressa em copiar ou em formular respostas às questões foram encontrados alguns erros ortográficos no desenvolvimento das tarefas escolares como: a) omissão de letra (pessos/pessoas); b) erros por apoio da grafia na oralidade (impréstimo/empréstimo; maxista/machista; adiquirir/adquirir); c) erros de acentuação (destroi/destrói; remedio/remédio) e d) erros na grafia de algumas letras, como no caso da letra "I" (I minúsculo grafado como $E$ minúsculo) e da letra "T" (letra sem o traço superior, tornando-se semelhante a letra L minúscula).

A ocorrência desses erros nos cadernos e trabalhos escolares não parece estar relacionada à interferência realizada pela freqüência com que os adolescentes teclam seus textos na Internet. Por outro lado, tais erros parecem vinculados a outros fatores como a distração e/ou velocidade de processamento da informação no contexto da tarefa, tendo em vista que as alterações encontradas não foram recorrentes ou sistemáticas de modo a indicar dificuldades no domínio da escrita ortográfica.

Maurício (14 anos), por exemplo, não gosta de escrever, deixando para copiar as anotações do professor perto do final da aula, implicando sempre a realização de uma cópia apressada, com uma caligrafia descuidada e erros que "escapam" devido à urgência em terminar logo a tarefa. Apesar de acessar diariamente a Internet e de escrever "muito mais em Internetês", como ele mesmo afirmou, e da pressa em terminar as tarefas escolares, contexto que poderia ser propício ao uso do seu Internetês, não foi observada qualquer transposição da escrita teclada para os seus registros escolares.

A não utilização da escrita da Internet nos registros escolares pelos adolescentes por nós entrevistados sugere que o possível emprego de tal escrita nos trabalhos escolares dos adolescentes não pode ser atribuído simplesmente ao hábito criado pela freqüência de seu uso na Internet. Em 
princípio, a escrita teclada é circunscrita ao contexto digital, não tendo função sociocomunicativa se aplicada a outro contexto, como por exemplo, o escolar:

Para mim, o Internetês é mais uma variação da língua portuguesa só sendo empregada em escritas informais. Ela é mais prática e aparece para facilitar, para escrever mais rápido, assim como foi na fala. Da mesma forma que vossa mercê se transformou em vós mecê, depois em você e hoje na net é VC. Eu uso para escrever mais rápido, para teclar mais rápido, para que a gente converse melhor, sem esperar um tempão (Lívia, 16 anos).

Uma tentativa de compreender a não-transposição do Internetês para o contexto escolar envolveria a internalização pelos adolescentes dos usos e práticas da escrita em uma determinada sociedade, bem como das finalidades relacionadas a tais práticas (Barré-De Miniac, 2003). A opção pelo uso de uma ou outra forma de escrita pelo adolescente perpassa por representações relacionadas ao conhecimento da linguagem escrita, à função da escrita no contexto em que se inscreve, ao produto que gera e à interação realizada.

Não costumo confundir os dois tipos de escrita (da Internet e da escola). Eu uso as abreviações, gírias e outras coisas na Internet, porque ali, todo mundo usa e tem que usar para poder escrever rápido. É uma maneira de escrever rápido para conversar com seus amigos, de agilizar os diálogos (Marina, 12 anos).

A compreensão sobre as diferentes práticas e finalidades associadas aos usos sociais da linguagem escrita permite ao adolescente utilizar a escrita de forma específica sem produzir o amalgamento de suas variadas possibilidades nos diferentes contextos sociocomunicativos.

\section{Discussão}

Linguagem escrita, cultura e história estão intrínseca e reciprocamente relacionadas (Bakhtin, 2000[1953]; Barré-De Miniac, 2003; Xavier, 2006). O computador como novo suporte da escrita vem despertando uma nova atitude face ao ato de escrever, permitindo aos seus usuários autonomia para manipularem intencionalmente os elementos lingüísticos da escrita padrão, produzindo formas não-convencionais de escrita que se tornam relevantes ao contexto interativo de comunicação digital (Freitas, 2000). A quantidade e a qualidade com que as variações escritas são produzidas são influenciadas pelas interações do grupo virtual, onde a faixa etária e, principalmente, o gênero digital utilizado exercem influência considerável nestes processos. 
Assim sendo, um usuário que não compartilhe desse modelo alternativo de expressão da linguagem escrita apresenta comumente dificuldades em compreender o conteúdo do texto teclado (Coscarelli, 2003), bem como em interagir com seus pares.

A cultura eletrônica redefine a oposição entre fala e escrita no processo de textualização a partir de diferentes aspectos que variam dos graus de formalidade e informalidade, às formulações lingüísticas relacionadas ao léxico e a sintaxe, como aos modos de produção e organização no tempo e espaço. Na escrita dos adolescentes na Internet há o predomínio da forma coloquial, com frases curtas para facilitar tanto a escrita como a leitura. Observamos ao longo dos textos teclados, a alteração da grafia das palavras pelo alongamento de letras, de forma a representar os aspectos prosódicos da linguagem oral, como a entonação. Através do uso de imagens e da manipulação gráfica do teclado do computador, o adolescente representa em sua escrita os elementos paralingüísticos que naturalmente acompanham a oralidade, como, por exemplo, a expressão facial. O alongamento de letras e uso de emoticons auxiliam o adolescente que escreve a explicitar na mensagem o seu estado emocional, indicando simbolicamente, se está triste $(:()$, alegre $(:))$, que está mandando um beijo $\left(:^{*}\right)$ ou que está muito aborrecido (:-\%!!!) (Danet, Ruedenberg, Gurion \& Rosenbaum-Tamari, 1998; Pereira \& Moura, 2005; Caiado, 2007; Merchant, 2001; Descy, 2007). Desta forma, o locutor expressa suas idéias e sentimentos sem precisar descrevê-los pela palavra escrita, fazendo com que seu interlocutor, ao ler seu texto, experimente a sensação de estarem conversando (Freitas, 2005; Merchant, 2001).

No emprego da escrita da Internet, as transgressões à língua padrão são produzidas de forma deliberada, indicando uma opção do usuário por uma forma econômica e ágil de produção textual. Neste sentido, em função do contexto digital em que ocorre e dos efeitos que pretende provocar no seu texto, não seria apropriado vincular a escrita teclada a uma utilização errônea da língua (Merchant, 2005; Freitas, 2000, 2005; Pereira \& Moura, 2005; Caiado, 2007).

Não foram observadas ocorrências de transposições do Internetês para as situações escolares, onde a escrita padrão se impõe como opção fundamental, mesmo estando os adolescentes pressionados pelo contexto 
escolar a escrever de forma rápida. Apesar de os adolescentes passarem bastante tempo conectados à Internet, interagindo através de uma escrita alternativa com seus amigos, a possibilidade de "desaprenderem" a escrita padrão do Português Brasileiro mostrou-se bastante reduzida. Os adolescentes revelaram conhecimento suficiente a respeito das diferenciações existentes entre os dois tipos de contexto de escrita: a padrão e a digital, sabendo de antemão quando, como e com quem devem utilizá-las (Charlot, 2000).

É provável que tal transposição, quando e se ocorrer, seja facilitada ou facultada pela validação ou tolerância que o contexto de comunicação para o qual a escrita teclada é transposta tenha quanto ao seu emprego. De maneira geral, parece existir de um processo de legitimação das escolhas lingüísticas voltadas para o emprego da escrita padrão para a produção textual na escola, semelhante ao estabelecimento de um "contrato didático", ou seja, a um sistema recíproco, muitas vezes implícito, de expectativas estabelecidas no contexto escolar em relação ao conhecimento e ao processo de aprendizagem (Brousseau, 1988; Chevallard, 1988).

Em síntese, os resultados apresentados no presente, embora ainda exploratórios, são indicativos da forma como os adolescentes vêm utilizando a escrita na Internet para interagirem uns com os outros. A escrita teclada parece ser vista pelos adolescentes como expressão, por excelência, das variações lingüísticas relacionadas ao caráter interativo da produção textual que a comunicação na Internet suscita (Caiado, 2007; Merchant, 2001). Seu emprego não parece consistir em erro ou registro deturpado da língua, uma vez que é mediado pelo entendimento que os adolescentes têm dos usos e práticas sociais relacionados à escrita (Barré-De Miniac, 2003). Assim, entendemos o Internetês como uma opção de uso da língua escrita, onde cada transgressão surge de forma deliberada pelos adolescentes ao longo de suas interações virtuais. Neste sentido, o uso recorrente pelos adolescentes da escrita teclada não afetaria necessariamente, por sua simples repetição, o uso da linguagem escrita em sua forma padrão nos contextos sociocomunicativos em que o emprego desta for requerido.

Novos estudos se fazem necessários no sentido de examinar de forma mais ampla e sistemática as hipóteses por nós discutidas em âmbito exploratório. Tais hipóteses dizem respeito principalmente à sensibilidade dos 
adolescentes aos usos sociais da escrita, bem como às expectativas estabelecidas no sistema escolar quanto ao emprego da escrita padrão e à diversidade lingüística. Desta forma, futuras investigações poderiam contemplar, por exemplo, a análise contrastiva dos discursos de professores e alunos, bem como contar com a participação de adolescentes provenientes de grupos, socioculturais distintos de forma a poder revelar uma maior variação e diferenciação dos contextos sociocomunicativos.

\section{Nota}

* Agradecemos ao MCT/CNPq (Ministério de Ciência e Tecnologia/ Conselho Nacional de Pesquisa) pelo apoio à condução do trabalho de pesquisa. À FAPERJ, através do Edital Cientista do Nosso Estado. Aos adolescentes e seus responsáveis pela confiança em nós depositada. Em especial, aos adolescentes com quem muito aprendemos através de sua generosa e ativa participação.

\section{Referências}

ARAÚJO, Júlio César (2006). O que meu aluno faz nesse tal de Orkut? Vida Educação, vol. 3, no 9, pp. 29-32.

BAKHTIN, Mikhail (2000[1953]). Os gêneros do discurso. In M. Bakhtin, Estética da Criação Verbal. São Paulo: Martins Fontes, pp. 277-326.

BARON, Naomi (2005). Discourse structures in instant messaging. In S. Herring, Computer-Mediated Conversation. Cresskill, NJ: Hampton Press.

BARRÉ-DE MINIAC, Christine (2003). Savoir lire ET écrire dans une société donnée. Revue Française de Linguistique Appliquée, vol. VIII, pp. 107-120.

BOLTER, Jay D. (2001). Writing Space: Computers, Hypertext, and the Remediation of Print. Hillsdale: Erlbaum.

BROUSSEAU, Guy (1988). Le contrat didactique: le milieu. Recherches en Didactique des Mathématiques, vol. 7, no 2, pp. 33-115.

CAIADO, Roberta V. R. (2007). A ortografia no gênero weblog: entre a escrita digital e a escrita escolar. In J. C. Araújo (Org.), Internet \& Ensino: Novos Gêneros, Outros Desafios. Rio de Janeiro: Lucerna, pp. 35-47.

CHARLOT, Bernard (2000). Da Relação com o Saber: Elementos Para Uma Teoria. Porto Alegre: Artmed.

CHEVALLARD, Yves (1988). Sur l'analyse didactique. Deux études sur lês notions de contrate et de situation. Publications de l'IREM d'Aix-Marseille, vol. 14. 
COSCARELLI, Carla V. (2003). Entre textos e hipertextos. In C. V. Coscarelli (Org.), Novas Tecnologias, Novos Textos, Novas Formas de Pensar. Belo Horizonte: Autêntica, pp.65-84.

COSTA, Sérgio Roberto (2005). (Hiper) textos ciberespaciais: mutações do/no lerescrever. Caderno Cedes, vol. 25, no 65, pp.102-116.

DANET, Brenda; RUEDENBERG, Lucia; GURION, Ben \& ROSENBAUM-TAMARI, Yehudit (1998). "Hmmm...Where's that smoke coming from?" Writing, play and performance on internet relay chat. In F. Sudweeks; M. McLaughlin \& R. Sheizaf (Orgs.), Network and Netplay: Virtual Groups on the Internet. Cambridge: MIT Press, pp. 41-76. [Em linha] [Acedido em 14 de Outubro de 2007, disponível em http://www.nicoladoering.de/Hogrefe/danet.htm].

DELL'ISOLA, Regina L. P. (2007). Retextualização de Gêneros Escritos. Rio de Janeiro: Lucerna.

DESCY, Don E. (2007). All aboard the internet: IM set to talk with you with text! TechTrends, vol. 51, no 1, pp. 3-6.

EISENKRAEMER, Raquel E. (2006). Leitura digital e linguagem cifrada dos internautas. Texto Digital, vol. 2, no 2.

FARMER, Robert (2003). Instant messaging - collaborative tool or educator's nightmare! Canadá: Mount Saint Vincent University. [Em linha] [Acedido em 20 de Outubro de 2007, disponível em http://www.unb.ca/naweb/proceedings/ 2003/PaperFarmer.html].

FREIRE, Fernanda M. P. (2003). A palavra (re)escrita e (re)lida via internet. In E. T. Silva; F. Freire; R. Q. Almeida \& S. F. Amaral, A Leitura nos Oceanos da Internet. São Paulo: Cortez, pp.19-32.

FREITAG, Raquel M. \& FONSECA E SILVA, Marineide (2006). Uma análise sociolingüística da língua utilizada na Internet: implicações para o ensino de língua portuguesa. Revista Intercâmbio. Vol. XV. São Paulo: LAEL/PUC-SP.

FREITAS, Maria Teresa A. (2005). A escrita na Internet: nova forma de mediação e desenvolvimento cognitivo? In M.T.A. Freitas \& S. R. Costa (Orgs.), Leitura e Escrita de Adolescentes na Internet e na Escola. Belo Horizonte: Autêntica, pp.29-36.

FREITAS, Maria Teresa A. (2000). A escrita de adolescentes na Internet. Revista de Psicologia Clínica, vol 12, no 2, pp. 171-188.

GREENFIELD, Patricia \& YAN, Zheng. (2006). Children, adolescents, and the Internet: a new field of inquiry. Developmental Psychology, vol. 42, no 3, pp. 391-394.

GROSS, Elisheva F. (2004). Adolescent Internet use: what we expect, what teens report. Journal of Applied Developmental Psychology, vol. 25, no 6, pp. 633-649.

$\mathrm{KOCH}$, Ingedore V. \& ELIAS, Vanda M. (2006). Ler e Compreender: os Sentidos do Texto. São Paulo: Contexto.

KOMESO, Fabiana (no prelo). Internetês para interneteiros: (velhas) questões sobre escrita. [Em linha] [Acedido em 14 de Outubro de 2007, disponível em http://gel.org.br/4publica-estudos-2007/sistema06/86.PDF]. 
LEE, Carmen K. (2007). Affordances and text-making practices in online instant messaging. Written Communication, vol.24, no 3, pp. 223-249.

LOTHERINGTON, Heather \& XU, Yejun (2004). How to chat in english and chinese: emerging digital language conventions. ReCALL, vol. 16, no 2, pp. 308-329.

MARCUSCHI, Luiz Antônio (2005a). Gêneros textuais: definição e funcionalidade. In A. P. Dionisio; A. R. Machado \& M. A. Bezerra (Orgs.), Gêneros Textuais e Ensino. Rio de Janeiro: Lucerna, pp. 19-36.

MARCUSCHI, Luiz Antônio (2005b). Gêneros textuais emergentes no contexto da tecnologia digital. In L. A. Marcuschi \& A. C. Xavier (Orgs.), Hipertexto e Gêneros Digitais. Rio de Janeiro: Lucerna, pp. 13-67.

MARCUSCHI, Luiz Antônio. (2006). Gêneros textuais: configuração, dinamicidade e circulação. In A. M. Karwoski; B. Gaydeczka \& K. S. Brito (Orgs.), Gêneros Textuais: Reflexões e Ensino. Rio de Janeiro: Editora Lucerna, pp. 23-36.

MENESES, Julio (2004). El caso de orkut.com: una reflexión sobre la exploración de nuevos caminos para la sociabilidad online en la tradición del estudio de las comunidades virtuales. [Em linha] [Acedido em 18 de Julho de 2007, disponível em http://www.cibersociedad.net/congres2004/index_es.html].

MERCHANT, Guy (2001). Teenagers in cyberspace: an investigation of language use and language change in internet chatrooms. Journal of Research in Reading, vol. 24, no 3, pp. 293-306.

MERCHANT, Guy (2005). Electric involvement: identity performance in children's informal digital writing. Discourse: Studies in the Cultural Politics of Education, vol. 26, no 3, pp. 301-314.

PEREIRA, Ana Paula M.S. \& MOURA, Mirtes Z.S. (2005). A produção discursiva nas salas de bate-papo: formas e características processuais. In M.T.A. Freitas \& S. R. Costa (Orgs.), Leitura e Escrita de Adolescentes na Internet e na Escola. São Paulo: Autêntica, pp.65-83.

WIKIPÉDIA. Verbete Orkut. [Em linha] [Acedido em 18 de Julho de 2007, disponível em http://pt.wikipedia.org/wiki/Orkut].

XAVIER, Antônio Carlos (2006). Prefácio. In J. C. Araújo (Org.), Internet \& Ensino: Novos Gêneros, Outros Desafios. Rio de Janeiro: Lucerna, pp. 11-14. 
WRITING USING A KEYBOARD X CONVENTIONAL WRITING IN TEXTUAL PRODUCTION: THE EXPERIENCE OF BRAZILIAN TEENAGERS

\begin{abstract}
The computer connected to the internet has been promoting great changes in written language. As a result of the use of instant communication devices, new text genres have been emerged along with specific linguistic features in writing, which make communication through digital texts more dynamic and functional. The present work discusses teenagers' use of written language on the internet as related to digital text genres in the context of an electronic culture. It is argued that the specific linguistic features of the written language on the internet would not be transposed to other discursive contexts unless implicit or explicitly acknowledged. This suggests that linguistic choices made by teenagers are sensitively related to the discursive contexts.
\end{abstract}

Keywords

Typing; Digital text genre; Electronic culture; Teenagers

ECRITURE SUR CLAVIER X ECRITURE CONVENTIONNELLE: L'EXPERIENCE DES ADOLESCENTS BRESILIENS

\title{
Résumé
}

L'ordinateur associé à l'internet est en train de produire des transformations sur l'acte d'écrire, conduisant la production écrite vers la rapidité et vitesse d'exécution. Comme conséquence de la demande d'utilisation des applicatifs de communication instantanée, surgissent de nouveaux genres textuels, qui investissent l'écriture de caractéristiques lingüistiques spécifiques, ayant pour but de rendre la communication par le texte digital, plus dynamique et fonctionnel. Le présent travail met em discussion l'usage de l'écriture sur clavier par les adolescents comme attachée au genre textuel digital, dans le contexte de la culture électronique, rendant possible la production discursive 
sur internet. L'argumentation est que l'écriture sur clavier ne serait nécessairement transposée aux autres contextes discursifs, comme par exemple le contexte scolaire, ce qui suggère alors l'ocurrence d'un processus de légitimité des choix lingüistiques en fonction du contexte sociocommunicatif.

Mots-clé

Écriture sur clavier; Genre textuel digital; Culture électronique; Adolescents

Recebido em Novembro/2007

Aceite para publicação em Janeiro/2009

Toda a correspondência relativa a este artigo deve ser enviada para: Ana Lucia Gomes, Rua Barão de Mesquita, 850 bloco B apt. 802. Andaraí, Rio de Janeiro. Brasil, CEP: 20540-004, Brasil. Telef.: 55 (21) 3238-3916, 55 (21) 9769-3003; E-mail: ms.alfg@gmail.com 